\title{
Umbilical Cord Tissue-Derived Cells as Therapeutic Agents
}

\author{
Olga Maslova, ${ }^{1,2}$ Miroslav Novak, ${ }^{3}$ and Peter Kruzliak ${ }^{3}$ \\ ${ }^{1}$ National Taras Shevchenko University of Kyiv, Kyiv, Ukraine \\ ${ }^{2}$ Hemafund Ltd., Lisozakhysna Street 5, Kyiv, Ukraine \\ ${ }^{3}$ International Clinical Research Center, St. Anne’s University Hospital and Masaryk University, Pekarska 53, \\ 65691 Brno, Czech Republic \\ Correspondence should be addressed to Peter Kruzliak; peter.kruzliak@savba.sk
}

Received 31 August 2014; Accepted 21 November 2014

Academic Editor: Pritha Ray

Copyright (c) 2015 Olga Maslova et al. This is an open access article distributed under the Creative Commons Attribution License, which permits unrestricted use, distribution, and reproduction in any medium, provided the original work is properly cited.

Although the characteristics of SC, including UC-derived cells, are a dramatically discussed issue, this review will focus particularly on some controversial issues regarding clinical utility of cells isolated from UC tissue. UC-derived cells have several advantages compared to other types and sources of stem cells. The impact of UC topography on cell characteristics is briefly discussed. The necessity to adapt existing methods of cell isolation and culturing to GMP conditions is mentioned, as well as possible cryopreservation of this material. Light is shed on some future perspectives for UC-derived cells.

\section{Introduction}

There is a plethora of papers covering the topic of stem cells (SC) and their potential for use in regenerative medicine [15]. To date various types of stem cells have been described in humans from a variety of tissues, including preimplantation embryos, foetuses, birth-associated tissues, and different adult tissues [6]. Based on biochemical and genomic markers, they can be broadly classified into embryonic stem cells (ESC), mesenchymal stem cells (MSCs), and haematopoietic stem cells (HPS). The so-called neonatal MSC sources, including the placenta, amniotic fluid, and UC, have fewer limitations than cells from other tissues. It has been shown that the cells in these organs are more similar to early embryonic cells, both in surface marker portrait and differentiation potential. The UC is rich in cell material and is the most homogeneous formation in comparison with other provisional organs [7].

One of the most promising sources of SC, UC tissue, has been discussed in different reviews and research papers. UCderived cells have been under thorough investigation since 1991 [8] and the view on their biology has been developing intensively [9-15]. Hundreds of clinical trials are currently carried out using cells obtained from UC tissue. Moreover, cord tissue is considered a commercialized product for cryobanking on a par with cord blood (CB) in some countries $[16,17]$. This cell population is mentioned as a source of cell material for usage in various fields of regenerative medicine $[18,19]$. Human UC is a rich source of stem and progenitor cells (MSCs) derived either from the cord tissue or from cord blood [20]. However, CB is mostly considered the source of haematopoietic stem cells (HSC) [21] and UC can be considered a better source of MSC [22]. Usually the cells obtained from UC tissue are referred to as mesenchymal stem cells or multipotent stromal cells, both abbreviated as MSCs. They completely meet the classical criteria for MSCs: plastic adhesion, positive marker expression (CD105, CD90, and CD73), and trilineage differentiation capacity [23, 24]. However, it has been shown in a number of works that these cell populations exhibit broader "stem features" than MSCs from adult sources $[25,26]$. Taking into account that the UC itself is far more available and ethically "clean" than other described SC sources, it becomes obvious that UC could be called a "stem cell goldmine."

Several excellent reviews focused on the characteristics of UC cells and clinical research are currently available. For example, the work of Kim et al. [27] describes in detail the main properties of UC-derived cells that allow them to be used in regenerative medicine. Moreover, this review provides very useful data on WJ-MSCs as therapeutic 
agents for different pathologies. Prasanna and Jahnavi [28] prepared a comprehensive review of the data regarding the regenerative and immunomodulatory characteristics of $\mathrm{WJ}$ MSCs. Bongso and Fong [29] carried out an in-depth analysis of the challenges and future clinical directions in relation to UC-derived cells. Nagamura-Inoue and He [30] summarized concisely the advantages and potential clinical utility of UCderived cells. All these reviews provide sufficient information on the ontogenesis of UC and properties of UC-derived cells such as surface marker expression, differentiation capacities, and paracrine potential. It must be mentioned that the differentiation capacities of UC-derived cells are significantly higher than originally thought when MSC research began, because every year there are new works on successful novel cell-type differentiation from UC-derived cells [31-33]. For example, one of the new papers is "Epimorphin-Induced Differentiation of Human UC Mesenchymal Stem Cells into Sweat Gland Cells" [34].

In order to avoid broad overlaps and repetition of information, it is planned that this paper will focus on some controversial issues.

\section{Topical Issues Related to Utility of UC-Derived Cells in Regenerative Medicine}

2.1. The Impact of UC Topography on Cell Characteristics. Unlike the adult organism, where mesenchyme is completely transformed into a variety of connective tissues, the UC, as a yolk sac and allantois derivative, contains the primitive form of extraembryonic mesenchyme. The cells in the UC are divided into different groups based either on the region of isolation (WJ, cord lining (CL), perivascular area (PA), etc.) or on the cell type (epithelial, stromal, smooth muscle, and endothelial cells) [69-71]. A range of authors describe differences in the morphofunctional characteristics of cells isolated from different anatomic areas of the UD (e.g., WJ, PA, CL, and vascular walls) [72-74]. However, the majority of papers that investigate and describe UC cells in vivo (in both animals and humans) are based on the use of accumulated fraction of cell material isolated from the whole UC tissue or WJ [75-78]. This is mainly due to the simplicity of isolating mesenchymal cells from the whole UC tissue, precluding the necessity for additional operations. Moreover, Mennan et al. [79] showed that cells from whole UC differentiated as, or better than, those isolated from individual cord regions and therefore have potential as a useful source for obtaining promising cell populations for further study. In their study, MSCs from four regions of the same cord (artery, vein, WJ, and CL), in addition to a mixed cell population from the whole cord, were isolated and compared for potential musculoskeletal cell therapy. MSCs were cultured from all individual cord regions, as well as enzymatically digested whole cord, demonstrated by their plastic adherence, flow cytometry profile, and ability to differentiate along osteogenic, adipogenic, and chondrogenic lineages. The growth kinetics and MSC immunoprofile showed no significant difference between cells from any of the populations (or isolates). Osteogenic and adipogenic differentiation studies showed variations between cord regions, with the best differentiation seen in WJ and whole cord. Chondrogenic differentiation showed little difference between cells isolated from different cord regions. Unfortunately there is not enough evidence for priority of any of the cord regions for clinical utility. It could be assumed that the most effective strategy nowadays is to use WJ for cells' isolation.

Nevertheless, undoubtedly, the research of mesenchymal cell subpopulations is still an important task for fundamental cell biology. The investigation of UC stem cell expression of known markers of the embryonic stage, such as Oct-4 and SSEA4, is also of special interest. A variety of authors introduced data relating to the expression of these markers by cells isolated from the UC [73, 80-82]. This was one of the main factors that demonstrated the special position of UC-derived SC and allowed the suggestion that the properties of these cells, in the ontogenetic sense, are closer to those of pluripotent embryonic cells than to those of adult multipotent cells. At the same time, there is much evidence of revaluation of expression of these markers in UC-derived cells. For instance, there were presumably some methodological inaccuracies concerning the level of expression of Oct-4. As summarized in Ryan et al. [83], critical examination of the Oct-4 literature prompts the suggestion that Oct- 4 expression in foetal MSC may be a case of "The Emperor's New Clothes," with early reports of (false) positive expression amplified in subsequent studies without critical attention to emerging refinements in knowledge and methodology. In turn, the role of SSEA4 could be another, for there is some new evidence of changes in the viewpoint regarding the influence of SSEA4 on proliferation of stem cells. The paper by $\mathrm{He}$ et al. [84] reveals that SSEA4 may display altered expression profiles in response to culture media containing FBS and may not be an essential marker of WJ-MSC pluripotency. It should be mentioned that expression of early embryonic transcript markers is not well correlated with the differentiation potential of MSC. In order to link the expression of these markers and differentiation abilities, relevant and scientifically sound evident should be enclosed. Various differentiation paths should be analyzed by morphological, biochemical, and most importantly the functional studies and experimentally supported.

It must be understood that the data on expression of markers by UC cells vary in different laboratories. It is possible that during these investigations the authors faced not only different methods but also heterogeneity of UC samples due to the individual features of the donors, including ethnic group differences and other unrevealed characteristics [85]. This issue is yet to be investigated, but the distinction of results achieved by different authors validates this explanation.

However, despite the necessity for more in-depth research of the molecular biological peculiarities of the functioning of different subpopulations of UC tissue, the efficiency of their use as therapeutic agents seems obvious. Thus, hundreds of clinical research projects using UC-derived cells have been registered to date, and there are even more preclinical research projects. For example, 283 studies can be found for "cord tissue" at https://clinicaltrials.gov/. Entering the search request "umbilical cord tissue cell clinical trial" at 
http://scholar.google.com/ leads to 44,500 results including patents and excluding citations. The variety of pathologies that assume using UC-derived cells is impressive.

2.2. Possible Mechanisms of Action. UC-MSC not only can be used in the direct cell-oriented way as a suspension but also can produce different chemofactors in a culture medium that could be used either as a conditioned medium for culturing other cell types or as a potential therapeutic substance $[86,87]$. It has been demonstrated that MSC culturing on WJ extract delays senescence through p53 and p16INK4a/pRb pathways [88]. The authors of this research suggest that WJ extract provided an ideal microenvironment for MSC culture expansion in vitro, preserved MSC properties by delaying MSC senescence, and allowed large numbers of MSCs to be obtained for basic research and clinical therapy. Additionally, these MSCs may become a kind of supportive environment for some other cell types. Stromal support for HSCs [89], spermatogonial SC, and ESC was observed [90]. According to Fan et al. [91], mesenchymal stromal cell supported UC blood ex vivo expansion, enhances regulatory $\mathrm{T}$ cells, and reduces graft versus host disease. Moreover, Lin et al. [92] have shown that the post-UC-cell medium enhances freeze-thaw survival and expansion of cryopreserved CD34+ cells.

Paracrine effects of WJ-MSC could be performed through multiple signalling pathways with different key molecules. These effects provide neuroprotection, angiogenesis, and enhanced regeneration. Functional validation showed that WJ-MSCs induced better neural differentiation and neural cell migration via a paracrine mechanism. It has been confirmed that NTF3, EGF, MDK, HBEGF, CXCL2, CXCL5, and FGF9 are more abundant in WJ-MSCs than in MSC from other sources [56]. As it has been demonstrated in [66], "human WJ-MSCs upregulated the mRNA transcript expression of TGF- $\beta 2$, hypoxia-inducible factor- $1 \alpha$, and plasminogen activator inhibitor-1 genes in normal skin fibroblasts in our culture conditions. Other genes involved in re-epithelialization, neovascularization and/or remodeling - including VEGF, fibroblast growth factor-2, connective tissue growth factor, collagen I and collagen III - were not changed. Decorin and TGF- $\beta 3$ also remained unaffected." Nascimento et al. [43] have concluded that the expression of angiogenesis-associated transcripts (subtypes of VEGF, angiopoietins, HGF, C-mET, bFGF, TGF- $\beta$, and PDGF$\mathrm{AB}$ ) in cord-derived cells is high. Therefore, several factors are most likely contributing for the cardioprotective effects observed in vivo and in vitro. More-directed work is already under way specifically to identify the role of each of the candidates. The same situation is with other effects of MSC: the possible candidate molecules are discussed but the precise mechanisms and signal pathways are not elucidated enough.

WJ-MSC-based therapy can be considered as a potential alternative to orthotopic liver transplantation for liver disease treatment. UC-derived cells have demonstrated a potential to differentiate into hepatocyte-like cells. The in vitro and in vivo use of UC-MSCs for liver cell therapy has been described [93]. This cell population displays some of hepatic markers characterizing the sequential steps of liver development. In treating liver cirrhosis, UC-MSCs act like antiinflammatory and antifibrosis agents by endogenous secreted metalloproteinases [27]. Potential treatment of cardiovascular diseases using WJ-derived cells is described [94]. Surgical treatment using nonautologous valves or conduits has many disadvantages, including obstructive tissue ingrowths and calcification of the implant, and consequently cardiovascular foetal tissue engineering focuses on the in vitro fabrication of autologous, living tissue with the potential to regenerate heart muscle [27]. WJ-derived cells are a promising cellular source for cartilage repair due to both their differentiation and immunomodulatory properties [27]. WJ-MSCs have been demonstrated to successfully differentiate into cells resembling mature chondrocytes. Their peculiar features of low immunogenicity and the potential to induce immune tolerance justify efforts towards the use of UC-derived cells in osteoarthritis, rheumatoid arthritis, and other disease settings. Recent tissue engineering studies have focused on the development of bioartificial nerve conduits to guide axonal regrowth. Given the intrinsic ability of activated Schwann cells to promote axonal regeneration in vivo, UC-MSC can successfully be used to derive mature Schwann cells for the regeneration of peripheral nerves. Schwann cells also support axonal regeneration, construct myelin, and contribute to functional recovery in a spinal cord injury model [27]. Moreover, it has been established that UC-derived cells could be of great interest in human perinatal disorders of the central nervous system. The influence on the immune system and the inflammation process is also widely discussed [95-97]. Another interesting question is the potential use of UCderived cells for anticancer therapy $[98,99]$. Today there is evidence of the potential influence of UC-derived cells on almost every physiological system (Table 1).

The healing potential of UC-derived cells, as well as other MSCs, in regenerative medicine could be associated with different mechanisms such as direct reparation and tissue remodelling, paracrine effects and influence on the microenvironment, and immunomodulation. In most cases, these influences can be combined. Furthermore, methods of analysis are not always capable of checking all stages of performance of the clinical effect that is why we can only evaluate the final result-the positive or negative influence of the treatment.

\section{Adaptation of Methods to GMP Conditions}

One of the prominent tendencies in modern cell therapy is standardization of methods and adaptation of these methods to good manufacturing practice (GMP). The question of standardizing cell-isolation methods is one of the most widely discussed issues [100-103]. The paper by Sart et al. [104] gives sufficient data on this topic. It is also covered elsewhere $[105,106]$. Usage of GMP-compliant conditions can make products safer for patients and researchers, but the price of cell products (that are not cheap even without such conditions) should be significantly higher. 
TABLE 1: Schematic summary of current data on the putative mechanisms of UC-derived cell action.

\begin{tabular}{|c|c|c|c|c|}
\hline \multirow[b]{2}{*}{ Objective of therapy } & \multirow{2}{*}{$\begin{array}{l}\text { Possible influence } \\
\text { Direct tissue } \\
\text { remodelling } \\
\text { (including 2D, 3D } \\
\text { biomaterials) }\end{array}$} & \multicolumn{3}{|c|}{ References } \\
\hline & & $\begin{array}{l}\text { “Type-like” cell } \\
\text { effects }\end{array}$ & $\begin{array}{l}\text { Paracrine } \\
\text { mechanisms }\end{array}$ & \\
\hline Liver & & + & + & $\begin{array}{l}\text { Campard et al., } 2008 \text { [35]; } \\
\text { Tsai et al., 2009 [36]; } \\
\text { Anzalone et al., } 2010[37] ; \\
\text { Shi et al., } 2012 \text { [38]; } \\
\text { Wang et al., } 2013[39]\end{array}$ \\
\hline $\begin{array}{l}\text { Heart and } \\
\text { cardiovascular system }\end{array}$ & + & & + & $\begin{array}{c}\text { Kadner et al., } 2002 \text { [40]; } \\
\text { Corrao et al., } 2013 \text { [41]; } \\
\text { López et al., } 2013 \text { [42]; } \\
\text { Nascimento et al., } 2014 \text { [43] }\end{array}$ \\
\hline $\begin{array}{l}\text { Kidneys and } \\
\text { excretory system }\end{array}$ & & & + & $\begin{array}{l}\text { Du et al., } 2012[44] \text {; } \\
\text { Song et al., } 2014 \text { [45] }\end{array}$ \\
\hline $\begin{array}{l}\text { Central and } \\
\text { peripheral nervous } \\
\text { systems }\end{array}$ & + & + & + & $\begin{array}{l}\text { Weiss et al., } 2003 \text { [46]; } \\
\text { Fu et al., } 2004 \text { [47]; } \\
\text { Fu et al., } 2006 \text { [48]; } \\
\text { Weiss et al., } 2006 \text { [49]; } \\
\text { Joyce et al., } 2010 \text { [50]; } \\
\text { Matsuse et al., } 2010 \text { [51]; } \\
\text { Carvalho et al., } 2011 \text { [52]; } \\
\text { Dongmei et al., } 2011 \text { [53] } \\
\text { Zhang et al., } 2011 \text { [54]; } \\
\text { Dalous et al., } 2012 \text { [55]; } \\
\text { Hsieh et al., } 2013 \text { [56]; } \\
\text { Taran et al., } 2014 \text { [57] }\end{array}$ \\
\hline Cartilage & + & & + & $\begin{array}{c}\text { Wang et al., } 2009 \text { [58]; } \\
\text { Arufe et al., } 2011 \text { [59]; } \\
\text { lo Iacono et al., } 2011 \text { [60] }\end{array}$ \\
\hline $\begin{array}{l}\text { Metabolic regulation, } \\
\text { immune system, and } \\
\text { autoimmune diseases }\end{array}$ & & & + & $\begin{array}{l}\text { Tyndall and Uccelli, } 2009 \text { [61]; } \\
\text { Mazzini et al., } 2010 \text { [62]; } \\
\text { Uccelli and Prockop, } 2010 \text { [63]; } \\
\text { Liu et al., 2014 [64] }\end{array}$ \\
\hline Skin & + & & + & $\begin{array}{c}\text { Shohara et al., } 2012 \text { [65]; } \\
\text { Arno et al., } 2014 \text { [66] }\end{array}$ \\
\hline $\begin{array}{l}\text { Lungs and respiratory } \\
\text { system }\end{array}$ & & & + & $\begin{array}{l}\text { Lee et al., } 2011 \text { [67]; } \\
\text { Weiss, } 2014 \text { [68] }\end{array}$ \\
\hline
\end{tabular}

Complying with GMPs requires precisely defining the production process(es) as well as the multiple criteria required for a quality final product. Such variables include the environment, staff training and qualification, and controls [107]. GMP-compliant processes, cell culturing and preparation to clinical use, should be performed in accordance with general requirements for pharmaceutical facilities (building architecture, air preparing and cleaning systems, special requirements to the personnel, etc.). Preference is given to xeno-free conditions of culturing. Design of new clinicalgrade approaches for obtaining cell-based products from stem cell sources, including UC, is widely discussed [108-111].

As Martins et al. [112] clearly emphasize, "Due to the novelty, complexity and technical specificity of cell therapy, specially tailored and harmonized regulations were necessary to ensure global availability of cellular products. Currently, in the European Union, the regulation (EC) No. 1394/2007 on Advanced Therapy Medicinal Products (ATMPs) lays down specific guidelines concerning centralized authorization, supervision, and pharmacovigilance. One of the most important requirements of ATMPs is the full characterization of the product. Safety is a major concern with this type of biopharmaceutical." For this reason, the authors of that work designed the ATMP with a registered UCX trademark. A method to consistently isolate, expand, and cryopreserve a well-characterized population of human UCderived MSCs has been successfully adapted. Expression profiling, immunophenotypic analyses, mixed lymphocyte reaction, karyotyping, and evaluation of teratoma-forming potential as well as differentiation, immune suppression, and treg conversion assays were performed. Moreover, the most suitable GMP-grade cryopreservation and recovery methods are proposed for this cell-based product. 


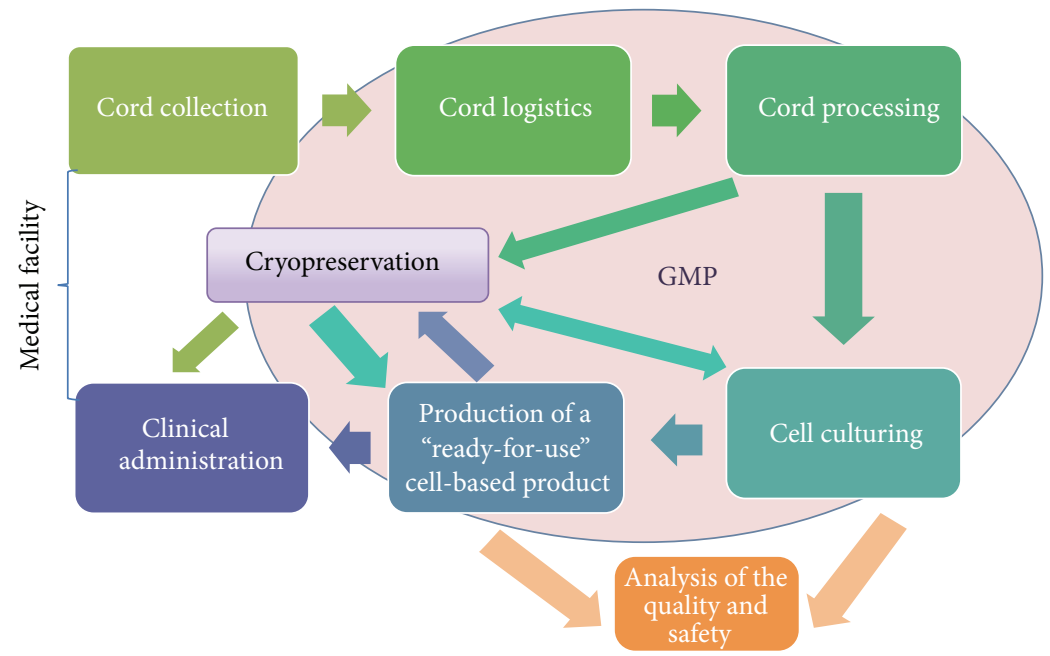

FIGURE 1: Schematic demonstration of the interconnections between the processes involved in obtaining of the product under GMP conditions.

3.1. Cryopreservation. The safest and most effective cryopreservation method is an important part of the research connected with clinical utility of all kinds of SC. A few recent papers focus on this problem. In Roy et al. [113], a serumfree formulation of $10 \%$ dimethyl sulfoxide (DMSO) and 0.2 M sucrose for cryopreservation of UC tissue was optimized. Slow freezing and rapid thawing were adopted. MSCs harvested from WJ of cryopreserved UC could undergo robust expansion, differentiate to mesodermal lineages, and express MSC-characteristic surface antigens. The cumulative cell yield, however, was lower compared to corresponding fresh cord tissue. Other papers gave alternative methods. Di Giuseppe et al. [114] carried out profound research on the cryopreservation effects on WJSCs proteome. It was demonstrated that frozen WJSCs showed qualitative and quantitative changes compared to fresh cells, expressing proteins involved in replication, cellular defence mechanism, and metabolism, which could ensure freeze-thaw survival. The results of this study could play a key role in elucidating possible mechanisms related to maintaining active proliferation and maximal cellular plasticity, thus making the use of WJSCs in cell therapy safe following biobanking. Consequently, establishment of the cryoconditions suitable for further GMP-compliant utility is of crucial importance.

Based on the available information we offer to depict the processes involved in obtaining the product under GMP conditions in Figure 1.

The way of umbilical cord in regenerative medicine begins and ends in medical institutions. At birth the material should be properly collected and then transported in suitable conditions to properly built and serviced gmp-grade facilities, where it should be processed for cells' isolation and culturing and preparation of medicinal product. The material might be cryopreserved at different stages: as a cord tissue, as a cell culture, or as a "ready-for-use" product. Moreover, the quality and safety studies need to be performed during manufacturing of the product. Some issues remain unresolved in the subject of choosing the necessary analyses set. What tests should the umbilical cord cellbased product pass? Apparently it depends on the source (autologous or allogeneic) of cord cells, the purpose of its use (type of pathologic condition), and so forth. Sterility and safety testing, immunophenotyping, testing of differentiation potential, karyotype analysis, telomerase activity assay, angiogenesis assays, various tumorigenicity assays, DNA-damage detecting assays, and so forth are among tests that could be established. The "ready-for-use" product is given to medical professionals and administrated in clinics.

One of the most important requirements of clinical grade cell-based products is the full characterization of the product. Safety is a major concern with this type of biopharmaceutical. The cell-based product must not cause infections, allergies, or malignancies [112]. One of the obstacles is variety of GMPcompliant conditions, because there are no strict standard requirements for production of cell-based products. It has been shown that MSCs processed under different variations of GMP-conditions could differ in their properties [115].

The most exigent part of above-mentioned interconnection is standardisation of procedures and successful cooperation between medical doctors, scientists, and pharmaceutical specialists.

\section{Future Perspectives and Challenges}

MSC in culture is a heterogeneous group of multipotent cells that are likely to acquire certain phenotypic properties after isolation from different tissues: the expression of a set of surface markers, adhesion to plastic, and the ability to induce differentiation [116]. Thus, an understanding of the cytological and biochemical specificities of MSC not only in culture but also in the living organism is a key issue that must be solved for more efficient and safer application of this material in clinical practice [117]. 
There are two prominent approaches towards stem cellbased therapeutics. The first can be characterized as scienceoriented and the second as medicine-oriented. The scienceoriented approach aims to reveal the deep molecular and cellular mechanisms of stem cell action in vitro and in vivo. The more characteristics that can be evaluated and fully described, the more features there are to analyse: here is their vector. And as there are more and more new findings and characteristics every year, presumably this analytical process could be virtually endless [118]. For example, another one-gene screening of WJ-MSCs has been performed by Mechiche Alami et al. [119]. The medicine-oriented approach focuses on the final effects; it targets the result, even without a profound understanding of the mechanisms behind the action of therapeutic agents. Thus, the latter approach is more risky.

Consequently, the most effective strategy should combine the above-mentioned methods of stem cell usage. Some main characteristics should be chosen for analysis (and they must be both informative and available for routine analysis), and then the most appropriate method of application should be selected and the therapeutic effect evaluated.

The most prominent future challenges and perspectives tend to concentrate on the field of standardization, GMPgrade optimization of all the relevant processes, and the search for procedures that minimally affect the stemness properties of cells.

\section{Conclusions}

The vast majority of UC-MSC clinical research is focused on remodelling of connective tissue injuries and repair of various organ malfunctions due to direct cell substitution or through certain paracrine interactions. UC-derived cells can be considered a mixture of cell types with broad therapeutic potential, the most distinguished of which are MSCs that possess properties combining foetal and adult SC features. Different authors have clear evidence about distinct properties of cells isolated from various regions of the UC. However, data from clinical research are mostly obtained using the whole UC or cells from the WJ. The necessity for standardization and adaptation of all methods to GMP conditions is pushing clinical research to create new, safer approaches and cellbased products. Development of cell and tissue cryobanking facilities allows the cord tissue as well as UC-derived cells to be cryogenically saved for further applications. There is a great need for new, highly informative approaches for evaluation of the cells' suitability for clinical administration. However, a balance between thorough scientific research and reasonable implementation of cell-based products into regenerative medicine is required the most.

\section{Abbreviations}

UC: Umbilical cord

MSC: Mesenchymal stem cell

SC: Stem cell

WJ: Wharton's jelly.

\section{Conflict of Interests}

The authors declare no conflict of interests.

\section{Acknowledgment}

This study was supported by the grant of the European Regional Development Fund-Project FNUSA-ICRC (no. CZ.1.05/1.1.00/02.0123).

\section{References}

[1] J. Ankrum and J. M. Karp, "Mesenchymal stem cell therapy: two steps forward, one step back," Trends in Molecular Medicine, vol. 16, no. 5, pp. 203-209, 2010.

[2] M. J. Hoogduijn, F. Popp, R. Verbeek et al., "The immunomodulatory properties of mesenchymal stem cells and their use for immunotherapy," International Immunopharmacology, vol. 10, no. 12, pp. 1496-1500, 2010.

[3] Y.-L. Si, Y.-L. Zhao, H.-J. Hao, X.-B. Fu, and W.-D. Han, "MSCs: biological characteristics, clinical applications and their outstanding concerns," Ageing Research Reviews, vol. 10, no. 1, pp. 93-103, 2011.

[4] A. I. Caplan and M. D. West, "Progressive approval: a proposal for a new regulatory pathway for regenerative medicine," Stem Cells Translational Medicine, 2014.

[5] S. Ma, N. Xie, W. Li, B. Yuan, Y. Shi, and Y. Wang, "Immunobiology of mesenchymal stem cells," Cell Death and Differentiation, vol. 21, no. 2, pp. 216-225, 2014.

[6] K. Bieback and I. Brinkmann, "Mesenchymal stromal cells from human perinatal tissues: from biology to cell therapy," World Journal of Stem Cells, vol. 2, no. 4, pp. 81-92, 2010.

[7] R. Hass, C. Kasper, S. Böhm, and R. Jacobs, "Different populations and sources of human mesenchymal stem cells (MSC): a comparison of adult and neonatal tissue-derived MSC," Cell Communication and Signaling, vol. 9, article 12, 2011.

[8] K. D. McElreavey, A. I. Irvine, K. T. Ennis, and W. H. I. McLean, "Isolation, culture and characterisation of fibroblast-like cells derived from the Wharton's jelly portion of human umbilical cord," Biochemical Society Transactions, vol. 19, no. 1, p. 29S, 1991.

[9] B. Pelletier, M. Moisant, and J. P. Zahnd, "Primary cultures of epithelial cells and long-term cultures of fibroblasts from the human umbilical cord: ultrastructural and immunocytochemical characterization," Comptes Rendus des Séances de la Société de Biologie et de ses Filiales, vol. 180, no. 4, pp. 447-459, 1986.

[10] K. Takechi, Y. Kuwabara, and M. Mizuno, "Ultrastructural and immunohistochemical studies of Wharton's jelly umbilical cord cells," Placenta, vol. 14, no. 2, pp. 235-245, 1993.

[11] A. K. Nanaev, G. Kohnen, A. P. Milovanov, S. P. Domogatsky, and P. Kaufmann, "Stromal differentiation and architecture of the human umbilical cord," Placenta, vol. 18, no. 1, pp. 53-64, 1997.

[12] K. Kobayashi, T. Kubota, and T. Aso, "Study on myofibroblast differentiation in the stromal cells of Wharton's jelly. Expression and localization of $\alpha$-smooth muscle actin," Early Human Development, vol. 51, no. 3, pp. 223-233, 1998.

[13] H.-S. Wang, S.-C. Hung, S.-T. Peng et al., "Mesenchymal stem cells in the Wharton's jelly of the human umbilical cord," Stem Cells, vol. 22, no. 7, pp. 1330-1337, 2004. 
[14] S. Karahuseyinoglu, O. Cinar, E. Kilic et al., "Biology of stem cells in human umbilical cord stroma: in situ and in vitro surveys," Stem Cells, vol. 25, no. 2, pp. 319-331, 2007.

[15] D. L. Troyer and M. L. Weiss, "Wharton's jelly-derived cells are a primitive stromal cell population," Stem Cells, vol. 26, no. 3, pp. 591-599, 2008.

[16] R. R. Taghizadeh, K. J. Cetrulo, and C. L. Cetrulo, "Wharton's Jelly stem cells: future clinical applications," Placenta, vol. 32, no. 4, pp. S311-S315, 2011.

[17] D. T. Harris, "Stem cell banking for regenerative and personalized medicine," Biomedicines, vol. 2, no. 1, pp. 50-79, 2014.

[18] T. Meyer, A. Pfeifroth, and B. Hocht, "Isolation and characterisation of mesenchymal stem cells in Wharton's jelly of the human umbilical cord: potent cells for cellbased therapies in paediatric surgery?" European Surgery, vol. 40, pp. 239-244, 2008.

[19] A. Kikuchi-Taura, A. Taguchi, T. Kanda et al., "Human umbilical cord provides a significant source of unexpanded mesenchymal stromal cells," Cytotherapy, vol. 14, no. 4, pp. 441-450, 2012.

[20] K. Bieback and H. Klüter, "Mesenchymal stromal cells from umbilical cord blood," Current Stem Cell Research \& Therapy, vol. 2, no. 4, pp. 310-323, 2007.

[21] V. Mirabet and P. Solves, "Cryopreservation of hematopoietic stem cells from umbilical cord blood for transplantation stem cells and cancer stem cells," Journal of Stem Cell Research \& Therapy, vol. 9, pp. 3-11, 2013.

[22] M. Zeddou, A. Briquet, B. Relic et al., "The umbilical cord matrix is a better source of mesenchymal stem cells (MSC) than the umbilical cord blood," Cell Biology International, vol. 34, no. 7, pp. 693-701, 2010.

[23] M. Dominici, K. Le Blanc, I. Mueller et al., "Minimal criteria for defining multipotent mesenchymal stromal cells. The International Society for Cellular Therapy position statement," Cytotherapy, vol. 8, no. 4, pp. 315-317, 2006.

[24] C.-Y. Fong, M. Richards, N. Manasi, A. Biswas, and A. Bongso, "Comparative growth behaviour and characterization of stem cells from human Wharton's jelly," Reproductive BioMedicine Online, vol. 15, no. 6, pp. 708-718, 2007.

[25] S. Angelucci, M. Marchisio, F. Di Giuseppe et al., "Proteome analysis of human Wharton's jelly cells during in vitro expansion," Proteome Science, vol. 8, article 18, 2010.

[26] C.-Y. Fong, L.-L. Chak, A. Biswas et al., "Human Wharton's jelly stem cells have unique transcriptome profiles compared to human embryonic stem cells and other mesenchymal stem cells," Stem Cell Reviews and Reports, vol. 7, no. 1, pp. 1-16, 2011.

[27] D.-W. Kim, M. Staples, K. Shinozuka, P. Pantcheva, S.-D. Kang, and C. V. Borlongan, "Wharton's jelly-derived mesenchymal stem cells: phenotypic characterization and optimizing their therapeutic potential for clinical applications," International Journal of Molecular Sciences, vol. 14, no. 6, pp. 11692-11712, 2013.

[28] S. J. Prasanna and V. S. Jahnavi, "Wharton's jelly mesenchymal stem cells as off-the-shelf cellular therapeutics: a closer look into their regenerative and immunomodulatory properties," The Open Tissue Engineering and Regenerative Medicine Journal, vol. 4, no. 1, pp. 28-38, 2011.

[29] A. Bongso and C.-Y. Fong, "The therapeutic potential, challenges and future clinical directions of stem cells from the Wharton's jelly of the human umbilical cord," Stem Cell Reviews and Reports, vol. 9, no. 2, pp. 226-240, 2013.

[30] T. Nagamura-Inoue and H. He, "Umbilical cord-derived mesenchymal stem cells: their advantages and potential clinical utility," World Journal of Stem Cells, vol. 6, no. 2, pp. 195-202, 2014.

[31] M. T. Conconi, P. Burra, R. Di Liddo et al., "CD105 $\left(^{+}\right)$cells from Wharton's jelly show in vitro and in vivo myogenic differentiative potential," International Journal of Molecular Medicine, vol. 18, no. 6, pp. 1089-1096, 2006.

[32] Y. Xu, S. Huang, K. Ma, X. Fu, W. Han, and Z. Sheng, "Promising new potential for mesenchymal stem cells derived from human umbilical cord Wharton's jelly: sweat gland celllike differentiative capacity," Journal of Tissue Engineering and Regenerative Medicine, vol. 6, no. 8, pp. 645-654, 2012.

[33] M. Choi, H.-S. Lee, P. Naidansaren et al., "Proangiogenic features of Wharton's jelly-derived mesenchymal stromal/stem cells and their ability to form functional vessels," The International Journal of Biochemistry \& Cell Biology, vol. 45, no. 3, pp. 560-570, 2013.

[34] R. Tao, T. J. Sun, Y. Q. Han, G. Xu, J. Liu, and Y. F. Han, "Epimorphin-induced differentiation of human umbilical cord mesenchymal stem cells into sweat gland cells," European Review for Medical and Pharmacological Sciences, vol. 18, no. 9, pp. 1404-1410, 2014.

[35] D. Campard, P. A. Lysy, M. Najimi, and E. M. Sokal, "Native umbilical cord matrix stem cells express hepatic markers and differentiate into hepatocyte-like cells," Gastroenterology, vol. 134, no. 3, pp. 833-848, 2008.

[36] P.-C. Tsai, T.-W. Fu, Y.-M. A. Chen et al., "The therapeutic potential of human umbilical mesenchymal stem cells from Wharton's jelly in the treatment of rat liver fibrosis," Liver Transplantation, vol. 15, no. 5, pp. 484-495, 2009.

[37] R. Anzalone, M. L. Iacono, S. Corrao et al., "New emerging potentials for human wharton's jelly mesenchymal stem cells: immunological features and hepatocyte-like differentiative capacity," Stem Cells and Development, vol. 19, no. 4, pp. 423-438, 2010.

[38] M. Shi, Z. Zhang, R. Xu et al., "Human mesenchymal stem cell transfusion is safe and improves liver function in acute-onchronic liver failure patients," Stem Cells Translational Medicine, vol. 1, no. 10, pp. 725-731, 2012.

[39] L. Wang, J. Li, H. Liu et al., "A pilot study of umbilical cord-derived mesenchymal stem cell transfusion in patients with primary biliary cirrhosis," Journal of Gastroenterology and Hepatology (Australia), vol. 28, no. 1, pp. 85-92, 2013.

[40] A. Kadner, S. P. Hoerstrup, J. Tracy et al., "Human umbilical cord cells: a new cell source for cardiovascular tissue engineering," Annals of Thoracic Surgery, vol. 74, no. 4, pp. S1422-S1428, 2002.

[41] S. Corrao, G. La Rocca, M. Lo Iacono et al., "New frontiers in regenerative medicine in cardiology: the potential of Wharton's jelly mesenchymal stem cells," Current Stem Cell Research \& Therapy, vol. 8, no. 1, pp. 39-45, 2013.

[42] Y. López, B. Lutjemeier, K. Seshareddy et al., "Wharton's jelly or bone marrow mesenchymal stromal cells improve cardiac function following myocardial infarction for more than 32 weeks in a rat model: a preliminary report," Current Stem Cell Research and Therapy, vol. 8, no. 1, pp. 46-59, 2013.

[43] D. S. Nascimento, D. Mosqueira, L. M. Sousa et al., "Human umbilical cord tissue-derived mesenchymal stromal cells attenuate remodeling after myocardial infarction by proangiogenic, antiapoptotic, and endogenous cell-activation mechanisms," Stem Cell Research \& Therapy, vol. 5, no. 1, article 5, 2014.

[44] T. Du, J. Cheng, L. Zhong et al., "The alleviation of acute and chronic kidney injury by human Wharton's jelly-derived 
mesenchymal stromal cells triggered by ischemia-reperfusion injury via an endocrine mechanism," Cytotherapy, vol. 14, no. 10, pp. 1215-1227, 2012.

[45] M. Song, J. Heo, J. Y. Chun et al., "The paracrine effects of mesenchymal stem cells stimulate the regeneration capacity of endogenous stem cells in the repair of a bladder-outletobstruction-induced overactive bladder," Stem Cells and Development, vol. 23, no. 6, pp. 654-663, 2014.

[46] M. L. Weiss, K. E. Mitchell, J. E. Hix et al., "Transplantation of porcine umbilical cord matrix cells into the rat brain," Experimental Neurology, vol. 182, no. 2, pp. 288-299, 2003.

[47] Y.-S. Fu, Y.-T. Shih, Y.-C. Cheng, and M.-Y. Min, "Transformation of human umbilical mesenchymal cells into neurons in vitro," Journal of Biomedical Science, vol. 11, no. 5, pp. 652-660, 2004.

[48] Y.-S. Fu, Y.-C. Cheng, M.-Y. A. Lin et al., "Conversion of human umbilical cord mesenchymal stem cells in Wharton's Jelly to dopaminergic neurons in vitro: potential therapeutic application for Parkinsonism," Stem Cells, vol. 24, no. 1, pp. 115124, 2006.

[49] M. L. Weiss, S. Medicetty, A. R. Bledsoe et al., "Human umbilical cord matrix stem cells: preliminary characterization and effect of transplantation in a rodent model of Parkinson's disease," Stem Cells, vol. 24, no. 3, pp. 781-792, 2006.

[50] N. Joyce, G. Annett, L. Wirthlin, S. Olson, G. Bauer, and J. A. Nolta, "Mesenchymal stem cells for the treatment of neurodegenerative disease," Regenerative Medicine, vol. 5, no. 6, pp. 933-946, 2010.

[51] D. Matsuse, M. Kitada, M. Kohama et al., "Human umbilical cord-derived mesenchymal stromal cells differentiate into functional schwann cells that sustain peripheral nerve regeneration," Journal of Neuropathology \& Experimental Neurology, vol. 69, no. 9, pp. 973-985, 2010.

[52] M. M. Carvalho, F. G. Teixeira, R. L. Reis, N. Sousa, and A. J. Salgado, "Mesenchymal stem cells in the umbilical cord: phenotypic characterization, secretome and applications in central nervous system regenerative medicine," Current Stem Cell Research and Therapy, vol. 6, no. 3, pp. 221-228, 2011.

[53] H. Dongmei, L. Jing, X. Mei et al., "Clinical analysis of the treatment of spinocerebellar ataxia and multiple system atrophycerebellar type with umbilical cord mesenchymal stromal cells," Cytotherapy, vol. 13, no. 8, pp. 913-917, 2011.

[54] L. Zhang, Y. Li, C. Zhang, M. Chopp, A. Gosiewska, and K. Hong, "Delayed administration of human umbilical tissuederived cells improved neurological functional recovery in a rodent model of focal ischemia," Stroke, vol. 42, no. 5, pp. 14371444, 2011.

[55] J. Dalous, J. Larghero, and O. Baud, “Transplantation of umbilical cord-derived mesenchymal stem cells as a novel strategy to protect the central nervous system: technical aspects, preclinical studies, and clinical perspectives., Pediatric research, vol. 71, no. 4, pp. 482-490, 2012.

[56] J.-Y. Hsieh, H.-W. Wang, S.-J. Chang et al., "Mesenchymal stem cells from human umbilical cord express preferentially secreted factors related to neuroprotection, neurogenesis, and angiogenesis," PLoS ONE, vol. 8, no. 8, Article ID e72604, 2013.

[57] R. Taran, M. K. Mamidi, G. Singh et al., "In vitro and in vivo neurogenic potential of mesenchymal stem cells Isolated from different sources," Journal of Biosciences, vol. 39, no. 1, pp. 157$169,2014$.
[58] L. Wang, K. Seshareddy, M. L. Weiss, and M. S. Detamore, "Effect of initial seeding density on human umbilical cord mesenchymal stromal cells for fibrocartilage tissue engineering," Tissue Engineering A, vol. 15, no. 5, pp. 1009-1017, 2009.

[59] M. C. Arufe, A. de La Fuente, J. Mateos, I. Fuentes, F. J. de Toro, and F. J. Blanco, "Analysis of the chondrogenic potential and secretome of mesenchymal stem cells derived from human umbilical cord stroma," Stem Cells and Development, vol. 20, no. 7, pp. 1199-1212, 2011.

[60] M. lo Iacono, R. Anzalone, S. Corrao et al., "Perinatal and wharton's jelly-derived mesenchymal stem cells in cartilage regenerative medicine and tissue engineering strategies," Open Tissue Engineering and Regenerative Medicine Journal, vol. 4, no. 1, pp. 72-81, 2011.

[61] A. Tyndall and A. Uccelli, "Multipotent mesenchymal stromal cells for autoimmune diseases: teaching new dogs old tricks," Bone Marrow Transplantation, vol. 43, no. 11, pp. 821-828, 2009.

[62] L. Mazzini, I. Ferrero, V. Luparello et al., "Mesenchymal stem cell transplantation in amyotrophic lateral sclerosis: a phase I clinical trial," Experimental Neurology, vol. 223, no. 1, pp. 229237, 2010

[63] A. Uccelli and D. J. Prockop, "Why should mesenchymal stem cells (MSCs) cure autoimmune diseases?" Current Opinion in Immunology, vol. 22, no. 6, pp. 768-774, 2010.

[64] X. Liu, P. Zheng, X. Wang et al., "A preliminary evaluation of efficacy and safety of Wharton's jelly mesenchymal stem cell transplantation in patients with type 2 diabetes mellitus," Stem Cell Research \& Therapy, vol. 5, article 57, 2014.

[65] R. Shohara, A. Yamamoto, S. Takikawa et al., "Mesenchymal stromal cells of human umbilical cord Wharton's jelly accelerate wound healing by paracrine mechanisms," Cytotherapy, vol. 14, no. 10, pp. 1171-1181, 2012.

[66] A. I. Arno, S. Amini-Nik, P. H. Blit et al., "Human Wharton's jelly mesenchymal stem cells promote skin wound healing through paracrine signaling," Stem Cell Research and Therapy, vol. 5, no. 1, article 28, 2014.

[67] J. W. Lee, X. Fang, A. Krasnodembskaya, J. P. Howard, and M. A. Matthay, "Concise review: mesenchymal stem cells for acute lung injury: role of paracrine soluble factors," Stem Cells, vol. 29, no. 6, pp. 913-919, 2011.

[68] D. J. Weiss, "Concise review: current status of stem cells and regenerative medicine in lung biology and diseases," Stem Cells, vol. 32, no. 1, pp. 16-25, 2014.

[69] A. Can and S. Karahuseyinoglu, "Concise review: human umbilical cord stroma with regard to the source of fetus-derived stem cells," Stem Cells, vol. 25, no. 11, pp. 2886-2895, 2007.

[70] R. Sarugaser, D. Lickorish, D. Baksh, M. M. Hosseini, and J. E. Davies, "Human umbilical cord perivascular (HUCPV) cells: a source of mesenchymal progenitors," Stem Cells, vol. 23, no. 2, pp. 220-229, 2005.

[71] J. Ennis, C. Götherström, K. le Blanc, and J. E. Davies, "In vitro immunologic properties of human umbilical cord perivascular cells," Cytotherapy, vol. 10, no. 2, pp. 174-181, 2008.

[72] K. Kita, G. G. Gauglitz, T. T. Phan, D. N. Herndon, and M. G. Jeschke, "Isolation and characterization of mesenchymal stem cells from the sub-amniotic human umbilical cord lining membrane," Stem Cells and Development, vol. 19, no. 4, pp. 491501,2010

[73] M. T. Conconi, R. D. Liddo, M. Tommasini, C. Calore, and P. P. Parnigotto, "Phenotype and differentiation potential of stromal populations obtained from various zones of human umbilical 
cord: an overview," Open Tissue Engineering and Regenerative Medicine Journal, vol. 4, no. 1, pp. 6-20, 2011.

[74] C. J. Hayward, J. Fradette, T. Galbraith et al., "Harvesting the potential of the human umbilical cord: isolation and characterisation of four cell types for tissue engineering applications," Cells Tissues Organs, vol. 197, no. 1, pp. 37-54, 2012.

[75] A. Petsa, S. Gargani, A. Felesakis, N. Grigoriadis, and I. Grigoriadis, "Effectiveness of protocol for the isolation of Wharton's Jelly stem cells in large-scale applications," In Vitro Cellular and Developmental Biology-Animal, vol. 45, no. 10, pp. 573-576, 2009.

[76] I. Majore, P. Moretti, F. Stahl, R. Hass, and C. Kasper, "Growth and differentiation properties of mesenchymal stromal cell populations derived from whole human umbilical cord," Stem Cell Reviews and Reports, vol. 7, no. 1, pp. 17-31, 2011.

[77] N. Tsagias, I. Koliakos, V. Karagiannis, M. Eleftheriadou, and G. G. Koliakos, "Isolation of mesenchymal stem cells using the total length of umbilical cord for transplantation purposes," Transfusion Medicine, vol. 21, no. 4, pp. 253-261, 2011.

[78] A. Marmotti, S. Mattia, M. Bruzzone et al., "Minced umbilical cord fragments as a source of cells for orthopaedic tissue engineering: an in vitro study," Stem Cells International, vol. 2012, Article ID 326813, 13 pages, 2012.

[79] C. Mennan, K. Wright, A. Bhattacharjee, B. Balain, J. Richardson, and S. Roberts, "Isolation and characterisation of mesenchymal stem cells from different regions of the human umbilical cord," BioMed Research International, vol. 2013, Article ID 916136, 8 pages, 2013.

[80] U. Nekanti, V. B. Rao, A. G. Bahirvani, M. Jan, S. Totey, and M. Ta, "Long-term expansion and pluripotent marker array analysis of Wharton's jelly-derived mesenchymal stem cells," Stem Cells and Development, vol. 19, no. 1, pp. 117-130, 2010.

[81] C. Tantrawatpan, S. Manochantr, P. Kheolamai, Y. U-pratya, A. Supokawe, and S. Issaragrisil, "Pluripotent gene expression in mesenchymal stem cells from human umbilical cord Wharton's jelly and their differentiation potential to neural-like cells," Journal of the Medical Association of Thailand, vol. 96, no. 9, pp. 1208-1217, 2013.

[82] T. Pirjali, N. Azarpira, M. Ayatollahi, M. H. Aghdaie, B. Geramizadeh, and T. Talai, "Isolation and characterization of human mesenchymal stem cells derived from human umbilical cord Wharton's jelly and amniotic membrane," International Journal of Organ Transplantation Medicine, vol. 4, no. 3, pp. 111116, 2013.

[83] J. M. Ryan, A. R. Pettit, P. V. Guillot, J. K. Y. Chan, and N. M. Fisk, "Unravelling the pluripotency paradox in fetal and placental mesenchymal stem cells: Oct- 4 expression and the case of the emperor's new clothes," Stem Cell Reviews and Reports, vol. 9, no. 4, pp. 408-421, 2013.

[84] H. He, T. Nagamura-Inoue, H. Tsunoda et al., "Stage-specific embryonic antigen 4 in wharton's jelly-derived mesenchymal stem cells is not a marker for proliferation and multipotency," Tissue Engineering Part A, vol. 20, no. 7-8, pp. 1314-1324, 2014.

[85] O. O. Maslova, N. S. Shuvalova, O. M. Sukhorada et al., "Heterogeneity of umbilical cords as a source for mesenchymal stem cells," Dataset Papers in Biology, vol. 2013, Article ID 370103, 4 pages, 2013.

[86] C.-Y. Fong, A. Biswas, A. Subramanian, A. Srinivasan, M. Choolani, and A. Bongso, "Human keloid cell characterization and inhibition of growth with human Wharton's jelly stem cell extracts," Journal of Cellular Biochemistry, vol. 115, pp. 826-838, 2014.
[87] C.-Y. Fong, K. Tam, S. Cheyyatraivendran et al., "Human Wharton's jelly stem cells and its conditioned medium enhance healing of excisional and diabetic wounds," Journal of Cellular Biochemistry, vol. 115, no. 2, pp. 290-302, 2014.

[88] H. Hao, G. Chen, J. Liu et al., "Culturing on wharton's jelly extract delays mesenchymal stem cell senescence through p53 and p16INK4a/pRb pathways," PLoS ONE, vol. 8, no. 3, Article ID e58314, 2013.

[89] C. Y. Fong, K. Gauthaman, S. Cheyyatraivendran, H. D. Lin, A. Biswas, and A. Bongso, "Human umbilical cord Wharton's jelly stem cells and its conditioned medium support hematopoietic stem cell expansion ex vivo," Journal of Cellular Biochemistry, vol. 113, no. 2, pp. 658-668, 2012.

[90] L.-L. Lu, Y.-J. Liu, S.-G. Yang et al., "Isolation and characterization of human umbilical cord mesenchymal stem cells with hematopoiesis-supportive function and other potentials," Haematologica, vol. 91, no. 8, pp. 1017-1028, 2006.

[91] X. Fan, F. P. Gay, S.-Y. Ong et al., "Mesenchymal stromal cell supported umbilical cord blood ex vivo expansion enhances regulatory $\mathrm{T}$ cells and reduces graft versus host disease," Cytotherapy, vol. 15, no. 5, pp. 610-619, 2013.

[92] H. D. Lin, A. Bongso, K. Gauthaman, A. Biswas, M. Choolani, and C.-Y. Fong, "Human Wharton's jelly stem cell conditioned medium enhances freeze-thaw survival and expansion of cryopreserved CD34+ cells," Stem Cell Reviews and Reports, pp. 112, 2013.

[93] I. Scheers, C. Lombard, M. Najimi, and E. M. Sokal, "Cell therapy for the treatment of metabolic liver disease: an update on the umbilical cord derived stem cells candidates," Open Tissue Engineering and Regenerative Medicine Journal, vol. 4, no. 1, pp. 48-53, 2011.

[94] O. V. Semenov and C. Breymann, "Mesenchymal stem cells derived from wharton's jelly and their potential for cardiovascular tissue engineering," The Open Tissue Engineering and Regenerative Medicine Journal, vol. 4, no. 1, pp. 64-71, 2011.

[95] M. L. Weiss, C. Anderson, S. Medicetty et al., "Immune properties of human umbilical cord Wharton's jelly-derived cells," Stem Cells, vol. 26, no. 11, pp. 2865-2874, 2008.

[96] M. Stubbendorff, T. Deuse, X. Hua et al., "Immunological properties of extraembryonic human mesenchymal stromal cells derived from gestational tissue," Stem Cells and Development, vol. 22, no. 19, pp. 2619-2629, 2013.

[97] J. Voswinkel, S. Francois, J.-M. Simon et al., "Use of mesenchymal stem cells (MSC) in chronic inflammatory fistulizing and fibrotic diseases: a comprehensive review," Clinical Reviews in Allergy \& Immunology, vol. 45, no. 2, pp. 180-192, 2013.

[98] R. S. Rachakatla, M. M. Pyle, R. Ayuzawa et al., "Combination treatment of human umbilical cord matrix stem cell-based interferon-beta gene therapy and 5-fluorouracil significantly reduces growth of metastatic human breast cancer in SCID mouse lungs," Cancer Investigation, vol. 26, no. 7, pp. 662-670, 2008.

[99] M. R. Loebinger and S. M. Janes, "Stem cells as vectors for antitumour therapy," Thorax, vol. 65, no. 4, pp. 362-369, 2010.

[100] C. K. Tong, S. Vellasamy, B. C. Tan et al., "Generation of mesenchymal stem cell from human umbilical cord tissue using a combination enzymatic and mechanical disassociation method," Cell Biology International, vol. 35, no. 3, pp. 221-226, 2011.

[101] I. Koliakos, N. Tsagias, and V. Karagiannis, "Mesenchymal cells isolation from Wharton's jelly, in perspective to clinical 
applications," Journal of Biological Research, vol. 16, pp. 194-201, 2011.

[102] P. Venugopal, S. Balasubramanian, A. S. Majumdar, and M. $\mathrm{Ta}$, "Isolation, characterization, and gene expression analysis of Wharton's jelly-derived mesenchymal stem cells under xenofree culture conditions," Stem Cells and Cloning: Advances and Applications, vol. 4, no. 1, pp. 39-50, 2011.

[103] P. Salehinejad, N. Banu Alitheen, A. M. Ali et al., "Comparison of different methods for the isolation of mesenchymal stem cells from human umbilical cord Wharton's jelly," In Vitro Cellular and Developmental Biology-Animal, vol. 48, no. 2, pp. 75-83, 2012.

[104] S. Sart, Y.-J. Schneider, Y. Li, and S. N. Agathos, "Stem cell bioprocess engineering towards cGMP production and clinical applications," Cytotechnology, vol. 66, no. 5, pp. 709-722, 2014.

[105] B. Arjmand and H. R. Aghayan, "Cell manufacturing for clinical applications," STEM CELLS, vol. 32, no. 9, pp. 2557-2558, 2014.

[106] B. M. Deasy, J. E. Anderson, and S. Zelina, Regulatory Issues in the Therapeutic Use of Stem Cells, InTech, 2013.

[107] L. Sensebé, M. Gadelorge, and S. Fleury-Cappellesso, "Production of mesenchymal stromal/stem cells according to good manufacturing practices: a review," Stem Cell Research and Therapy, vol. 4, no. 3, article 66, 2013.

[108] B. Philippe, S. Luc, P.-B. Valérie, R. Jérôme, B.-R. Alessandra, and C. Louis, "Culture and use of mesenchymal stromal cells in phase I and II clinical trials," Stem Cells International, vol. 2010, Article ID 503593, 8 pages, 2010.

[109] L. Sensebé, P. Bourin, and K. Tarte, "Good manufacturing practices production of mesenchymal stem/stromal cells," Human Gene Therapy, vol. 22, no. 1, pp. 19-26, 2011.

[110] C. A. Herberts, M. S. G. Kwa, and H. P. H. Hermsen, "Risk factors in the development of stem cell therapy," Journal of Translational Medicine, vol. 9, article 29, 2011.

[111] A. Inamdar, “Therapeutic application of clinical grade umbilical cord tissue derived mesenchymal stem cells for human diseases," Journal of Stem Cell Research \& Therapy, vol. 3, article 5, 2013.

[112] J. P. Martins, J. M. Santos, J. M. D. Almeida et al., "Towards an advanced therapy medicinal product based on mesenchymal stromal cells isolated from the umbilical cord tissue: quality and safety data," Stem Cell Research \& Therapy, vol. 5, article 9, 2014.

[113] S. Roy, S. Arora, P. Kumari, and M. Ta, "A simple and serumfree protocol for cryopreservation of human umbilical cord as source of Wharton's jelly mesenchymal stem cells," Cryobiology, vol. 68, no. 3, pp. 467-472, 2014.

[114] F. Di Giuseppe, L. Pierdomenico, E. Eleuterio et al., "Cryopreservation effects on Wharton's jelly stem cells proteome," Stem Cell Reviews and Reports, vol. 10, no. 3, pp. 429-446, 2014.

[115] C. Menard, L. Pacelli, G. Bassi et al., "Clinical-grade mesenchymal stromal cells produced under various good manufacturing practice processes differ in their immunomodulatory properties: standardization of immune quality controls," Stem Cells and Development, vol. 22, no. 12, pp. 1789-1801, 2013.

[116] P. Wuchter, W. Wagner, and A. D. Ho, "Mesenchymal stem cells: an oversimplified nomenclature for extremely heterogeneous progenitors," Regenerative Medicine, vol. 3, no. 3, pp. 377-395, 2011.

[117] O. O. Maslova, "Current view of mesenchymal stem cells biology (brief review)," Biopolymers and Cell, vol. 28, no. 3, pp. 190-198, 2012.
[118] V. A. Kordium, V. I. Andrienko, O. A. Maslova et al., "Fundamental gap in fundamental biology," Biopolymers and Cell, vol. 27, no. 3, pp. 235-245, 2011.

[119] S. Mechiche Alami, F. Velard, F. Draux et al., "Gene screening of Wharton's jelly derived stem cells," Bio-Medical Materials and Engineering, vol. 24, no. 1, supplement, pp. 53-61, 2014. 

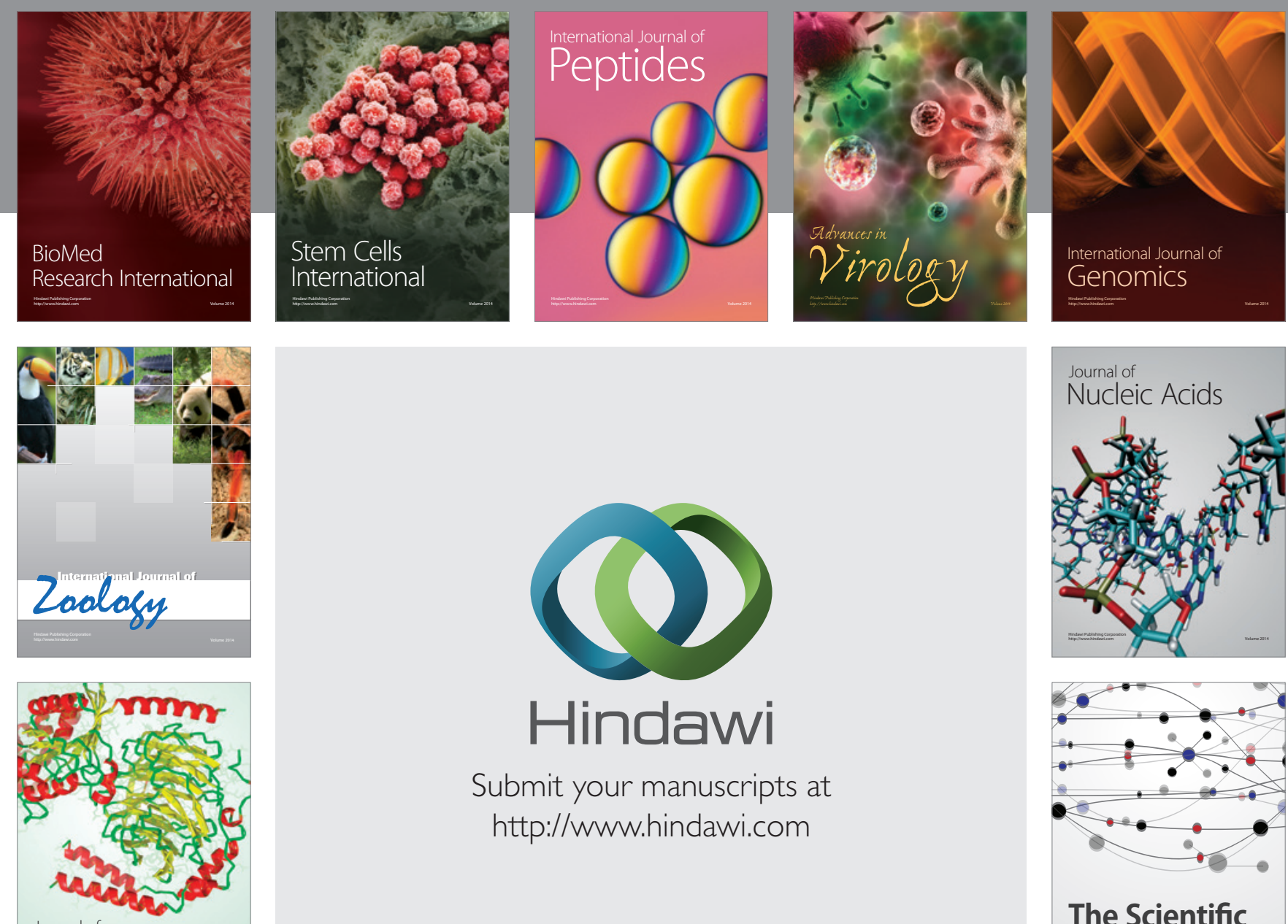

Submit your manuscripts at

http://www.hindawi.com

Journal of
Signal Transduction
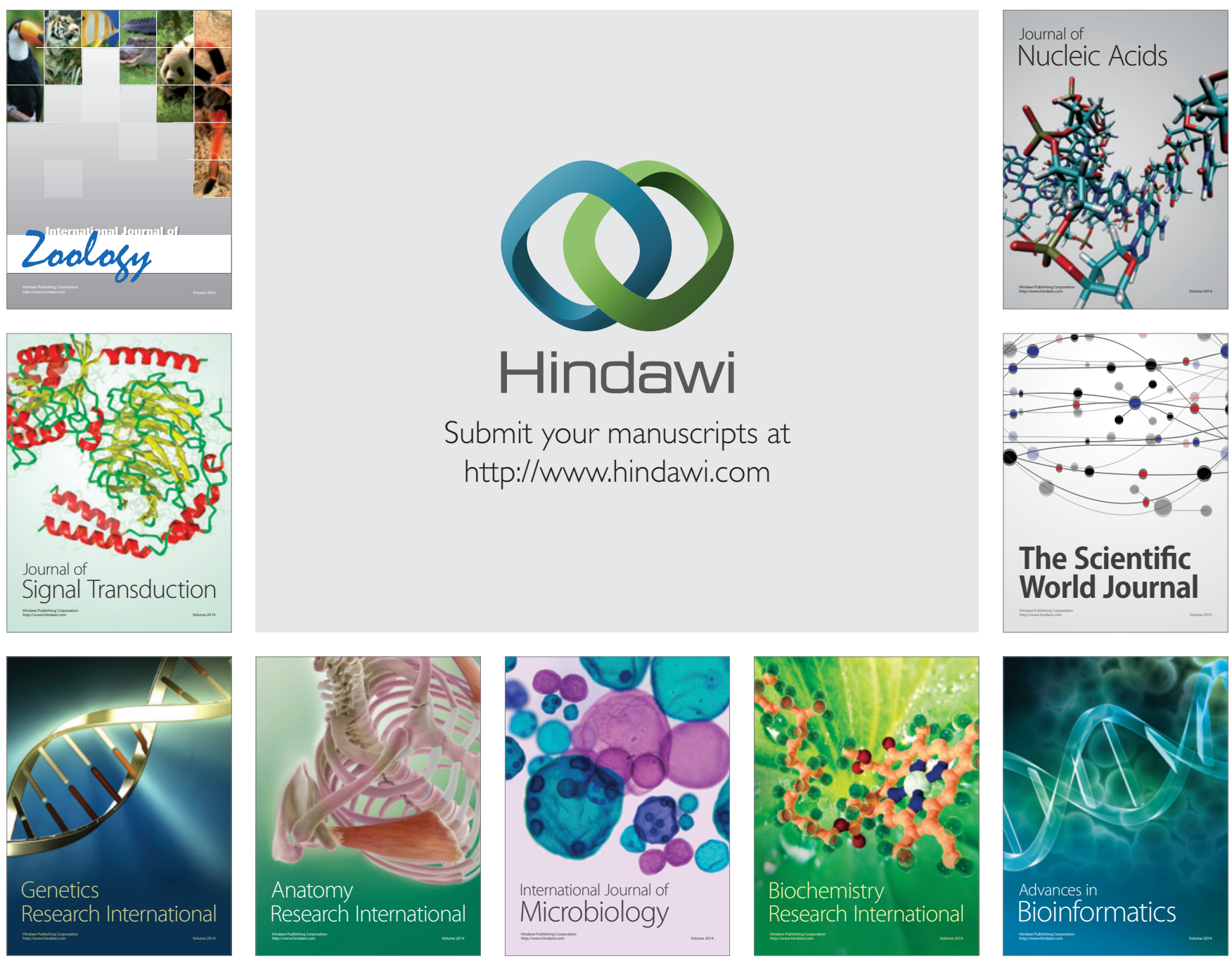

The Scientific World Journal
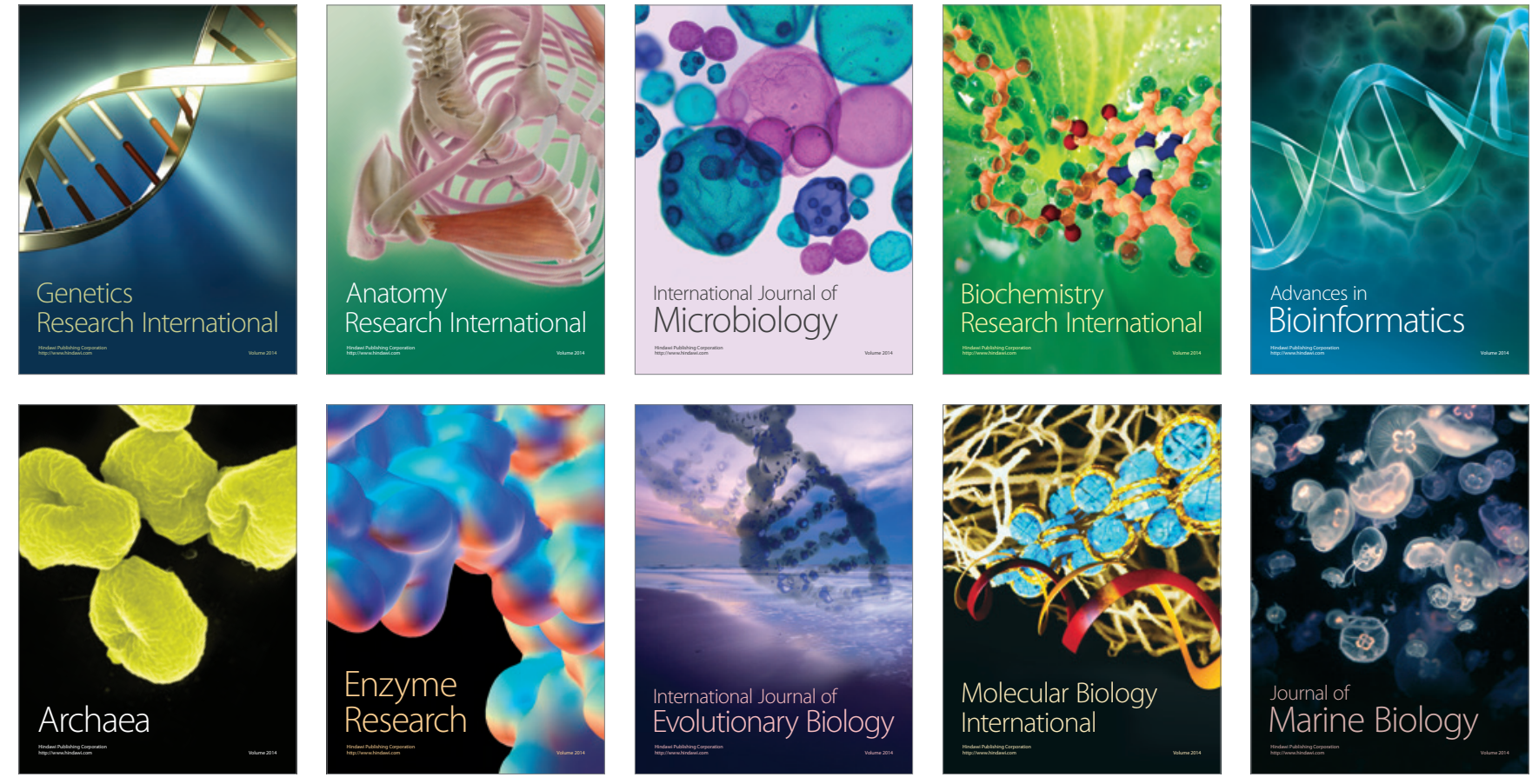